\title{
Fibronectin-Cleaving Activity in Bronchial Secretions of Patients with Cystic Fibrosis
}

\author{
Susanne Suter, U. B. Schaad, J. J. Morgenthaler, \\ I. Chevallier, and H. P. Schnebli
}

\author{
From the Department of Pediatrics, Children's Hospital, \\ University of Geneva, Geneva; the Department of Pediatrics, \\ Children's Hospital, University of Bern, and the Central \\ Laboratory, Swiss Red Cross, Bern; and the CIBA-GEIGY \\ Research Institute, Basel, Switzerland
}

\begin{abstract}
In cystic fibrosis, colonization of the airways with Pseudomonas aeruginosa follows colonization with Staphylococcus aureus and is related to accelerated deterioration of pulmonary function. Because $P$. aeruginosa adheres better to cell surfaces devoid of fibronectin, we searched for fibronectin-cleaving activity in bronchial secretions and saliva from 24 patients with cystic fibrosis who were followed up for $4.5 \mathrm{y}$ and from two control groups. Proteolytic activity against ${ }^{125}$ I-labeled fibronectin was continuously present in cystic fibrosis bronchial secretions; significantly higher fibronectin-cleaving activity was found in older vs. younger patients, in patients with advanced disease stages determined by a five-stage scoring system, and in those colonized with $P$. aeruginosa. The fibronectin-cleaving activity was due to neutrophil elastase and cathepsin G. Cystic fibrosis bronchial secretions had proteolytic activity against surface fibronectin of airway mucosal cells. Thus fibronectin-cleaving activity of bronchial secretions rather than of saliva may favor $P$. aeruginos colonization of the upper respiratory tract in individuals with cystic fibrosis.
\end{abstract}

Most individuals with cystic fibrosis who survive beyond the neonatal period die from respiratory failure, which is the consequence of chronic, progressively destructive bronchitis [1-3]. Clinical and pathological observations show extensive tissue destruction in the airways, which first causes obstruction and obliteration of small airways and thereafter destruction of the walls of large airways [4, 5]. Early in the disease course the bacterial pathogens frequently found in the bronchial secretions are Staphylococcus aureus and Haemophilus influenzae. Later the airways of these subjects are invariably colonized with Pseudomonas aeruginosa, an event that initiates an acclerated deterioration of lung functions [3] as well as an excessive systemic immune response [6]. These pathogens cannot be eliminated from the airways by antimicrobial therapy, and because the deleterious effect of $P$. aeruginosa infection in individuals with cystic fibrosis is well established, the identification of factors favoring colonization of the airways with $P$. aeruginosa is important. Coloniza-

Received for publication 29 October 1987 and in revised form 27 January 1988.

This work was supported by grants 3.816-0.84 and 3.850-0.86 from the Swiss National Research Foundation.

We thank Dr. A. Baici for suggestions and P. Schilling for manuscript preparation.

Please address requests for reprints to Dr. Susanne Suter, Clinique Universitaire de Pédiatrie, 30, bd de la Cluse, 1211 Geneva 4, Switzerland. tion of the upper respiratory tract with bacterial pathogens is achieved by binding of bacteria to epithelial cell surfaces. Several experimental studies have shown that the type of bacteria binding to epithelial surfaces is influenced by the presence of fibronectin, a glycoprotein on the cell surface [7-11]. The absence of fibronectin on epithelial cell surfaces from patients with cystic fibrosis [9] as well as from seriously ill patients with acute respiratory failure [10] correlated with increased adherence of $P$. aeruginosa to buccal epithelial cells. In these studies a parallel increase in activity of salivary proteases was demonstrated, and it was suggested that salivary proteases were the source of fibronectin-cleaving activity in these patients. However, in individuals with cystic fibrosis, not only saliva but also bronchial secretions may be the source of proteolytic activity [11-13].

We therefore attempted to quantitate and identify the fibronectin-cleaving enzymes in cystic fibrosis bronchial secretions and saliva in comparison with those from a control group of patients with chronic bronchitis. We also determined the proteolytic effect of cystic fibrosis bronchial secretions on cell surface fibronectin of airway mucosal cells of human lung tissue.

\section{Patients and Methods}

Study group. Twenty-four patients with cystic fibrosis attending the cystic fibrosis clinic or hospitalized at the Children's Hospitals of the Universities 
of Bern (Switzerland) and Geneva were prospectively included in the study since 1982 . The diagnosis of cystic fibrosis had been established by clinical features of the disease and was confirmed by sweat concentrations of $\mathrm{Na}^{+}$and $\mathrm{Cl}^{-}$of $>70 \mathrm{mEq} / \mathrm{L}$. The mean age of the patients was $12.7 \mathrm{y}$ (range, 15 mo to $21 \mathrm{y}$ ). Cultures of sputum from nine patients were positive mainly for S. aureus; other pathogens isolated included $H$. influenzae, $\beta$-hemolytic Streptococcus group A, and Escherichia coli. The mean age of these patients was 8.1 y (range, 15 mo to $15 \mathrm{y}$ ). Fifteen patients had cultures of sputum positive for $P$. aeruginosa; other pathogens isolated from these patients were $S$. aureus and Aspergillus fumigatus. The mean age of this group was $15.5 \mathrm{y}$ (range, 5.5-20 y). All patients who were colonized with $P$. aeruginosa were hospitalized three times per year for iv antimicrobial therapy.

Clinical and radiographic staging of cystic fibrosis was done by one of us, unaware of the laboratory results, with use of a five-stage scoring system [14], based on physical activity, general physical condition and bacteriology of sputum, signs of pulmonary disease, radiological lung involvement, and gastrointestinal manifestations. Each parameter was assigned a maximum of 5 points, with the highest score indicating the best status. Severity of the disease was graded in five stages (I-V). Radiographic scoring was done with the scoring system of Chrispin and Norman [15]. The highest stage (V) corresponds to poor pulmonary condition and advanced radiographic alterations of cystic fibrosis.

Control groups. Two control groups were also included in the study: one group included 16 patients with acute exacerbations of chronic bronchitis and bronchiectases, as documented by chronic cough, purulent sputum, positive chest findings, and roentgenograms. In nine patients, bronchiectases had been documented by bronchography or bronchoscopy. The mean age of the patients was 45 y (range, 956 y). Pathogens isolated from sputum included $H$. influenzae, Streptococcus pneumoniae, E. coli, $S$. aureus, and Aspergillus. The second control group included 10 patients who had chronic bronchitis without acute exacerbation (all of whom were smokers), as documented by chronic cough and increased amounts of nonpurulent sputum. These patients produced sputum that was negative when cultured for bacterial pathogens. The mean age of these patients was 68 y (range, 41-90 y).

Specimens. From all these patients, bronchial secretions were collected according to the following protocol: Fresh morning sputum was obtained during morning chest physiotherapy. For the patients with cystic fibrosis the number of samples collected per patient ranged from four to 22 over a period of $4.5 \mathrm{y}$. From two patients with cystic fibrosis and six patients with chronic bronchitis a sample of morning sputum and a sample obtained by bronchoscopy were collected on the same day. None of the patients received mucolytic treatment during the study period.

Cultures and identifications of bacteria from bronchial secretions were done according to wellestablished methods [16]. The secretions were mixed with a half volume of sterile $0.9 \% \mathrm{NaCl}$ and shaken by hand for $1 \mathrm{~min}$; the mixture was then centrifuged at $1000 \mathrm{~g}$ until the supernatant was clear. The supernatants were stored at $-70 \mathrm{C}$ until tested, and the total protein concentration was determined by a standard method (Biorad, Richmond, Calif). Ten bronchial secretions had been subjected to ultracentrifugation at $30000 \mathrm{~g}$ for $30 \mathrm{~min}$ without prior dilution, and the enzymatic activities were measured in these supernatants.

We also collected saliva from 18 healthy individuals and from 14 patients with cystic fibrosis (11 colonized with $P$. aeruginos $a$ and three not colonized with $P$. aeruginosa); these samples were centrifuged without prior dilution. The saliva of patients with cystic fibrosis was obtained during a cough-free period after chest physiotherapy, and only saliva that was macroscopically free from bronchial secretions was examined. No stimulus was used for stimulating production of saliva.

Lung tissue was obtained at autopsy from an eightmonth-old child without cystic fibrosis and without lung disease.

Three strains of $P$. aeruginosa, isolated from our patients with cystic fibrosis, that secreted bacterial elastase [11] were cultured in Mueller-Hinton broth for $24 \mathrm{~h}$; the culture supernatant was obtained by centrifugation at $8000 \mathrm{~g}$ for $20 \mathrm{~min}$.

Assessment of fibronectin-cleaving activity of bronchial secretions and saliva. Fibronectin was purified from human plasma [17] and radiolabeled with ${ }^{125}$ I [18] (Amersham Corp., Amersham, England). About $250000 \mathrm{cpm}$ of ${ }^{125}$ I was incorporated into $1 \mu \mathrm{g}$ of purified fibronectin. ${ }^{125}$ I-Labeled fibronectin ( ${ }^{125}$ I-fibronectin) was then coupled with CNBr-activated Sepharose ${ }^{\circledR B}$ (Pharmacia Fine Chemicals, Uppsala, Sweden). ${ }^{125}$ I-Fibronectin- 
Sepharose beads corresponding to $250000 \mathrm{cpm}$ were then suspended in $500 \mu \mathrm{L}$ of Dulbecco's PBS (pH 7.4) and incubated at $37 \mathrm{C}$ with $10 \mu \mathrm{L}$ of bronchial secretion, saliva, or purified neutrophil enzymes for $4 \mathrm{~h} .{ }^{125}$ I-Fibronectin fragments were separated from ${ }^{125}$ I-fibronectin still bound to Sepharose by centrifugation at $8000 \mathrm{~g}$ for $5 \mathrm{~min}$. Proteolysis of fibronectin was expressed as a percentage of the $\mathrm{cpm}$ in the supernatant divided by the cpm of the total sample. Spontaneous release of ${ }^{125} \mathrm{I}$ from fibronectin was measured simultaneously $(<2 \%)$ and subtracted from the results. The time course of degradation of ${ }^{125}$ I-fibronectin by bronchial secretions and by purified neutrophil enzymes was similar and showed that the enzymatic reaction was not linear; ${ }^{125}$ I-fibronectin fragments were rapidly released over the first minute of incubation, followed by slower release over a 4-h period.

For characterizing the fibronectin fragments generated by bronchial secretions, the fragments produced by proteolysis of purified (unlabeled) fibronectin by a pool of cystic fibrosis bronchial secretions over time was compared with the fragments generated by a mixture of purified elastase (three parts) and cathepsin G (one part). The fragments were separated with PAGE [19]. After electrophoresis the gels were incubated in $25 \mathrm{mM}$ Tris and $20 \%$ methanol ( $\mathrm{pH} \mathrm{10.4)} \mathrm{for} 15 \mathrm{~min}$, and the proteins were transferred to Novilon ${ }^{\circledR}$ membranes (Millipore Corp., Bedford, Mass) by using a Multiphor II Novablot ${ }^{\circledR}$ system (LKB, Bromma, Sweden) at $150 \mathrm{~mA}$ for 90 $\min$ [20]. The membrane was then slowly shaken in a blocking buffer (10 $\mathrm{m} M$ Tris, $1 \mathrm{~m} M$ EDTA, 133 $\mathrm{m} M \mathrm{NaCl}, 10 \%$ skim milk, $0.05 \%$ Triton X-100, and $2 \%$ sodium azide) at room temperature ( $~ 23 \mathrm{C}$ ) for $2 \mathrm{~h}$. Subsequently the membrane was incubated in skim milk (Difco, Detroit) containing an antibody to fibronectin raised in rabbits (Behring, Marburg, Federal Republic of Germany) at a dilution of 1:4000 followed by three washing steps in PBS ( $\mathrm{pH}$ 7.4), $\mathrm{Ca}^{++}$ and $\mathrm{Mg}^{++}$free. During the next step the Novilon membrane was incubated in skim milk containing an antibody to rabbit IgG bound to alkaline phosphatase (Sigma, St. Louis) at a dilution of 1:2000 for $2 \mathrm{~h}$. After three washing steps in $\mathrm{Ca}^{++}$- and $\mathrm{Mg}^{++}$free PBS, the membrane was incubated in $50 \mathrm{mM}$ Tris ( $\mathrm{pH} \mathrm{8)}$ for $10 \mathrm{~min}$ and exposed to the chromogenic substrate (naphthol AS-MX [ $40 \mathrm{mg}]$ and fast red salt [ $80 \mathrm{mg}$; both from Sigma] in $50 \mathrm{mM}$ Tris). The reaction was stopped by washing the Novilon membrane in tap water for $10 \mathrm{~min}$. Molecular weights were monitored with standard proteins (Biorad), which were revealed with amido-black staining.

Zymographs. To identify fibronectin-cleaving enzymes in cystic fibrosis bronchial secretions, we modified previously published methods [21, 22] for zymographs. Purified fibronectin $(1.5 \mathrm{mg} / \mathrm{mL})$ was added to a $7.5 \%$ (wt/vol) polyacrylamide gel before polymerization. The stacking gel contained no fibronectin. One microliter of a pool of cystic fibrosis bronchial secretions, purified elastase, cathepsin $\mathrm{G}$, or a mixture (3:1) of purified elastase and cathepsin $\mathrm{G}$ was added to $9 \mu \mathrm{L}$ of sample buffer [21] and electrophoresed through the fibronectin-containing gel at $4 \mathrm{C}$ for $5 \mathrm{~h}$ at $170 \mathrm{~V}$ without prior heating of the samples. SDS was then removed from the gel by incubation of the gel in $2.5 \%$ Triton X-100 for $1 \mathrm{~h}$. Thereafter the gel was incubated at $37 \mathrm{C}$ for $16 \mathrm{~h}$ in $0.1 M$ glycine, $\mathrm{pH} 8.3,7.4$, or 6.8 . Proteins were transferred to Novilon membranes, and fibronectin was revealed as described above. With this procedure the location to which a fibronectin-degrading protease had migrated was seen as a clear band, in which copolymerized fibronectin had been degraded. In control experiments, samples heated to $90 \mathrm{C}$ for 15 min were tested, and in others the Novilon membrane was incubated in $2 \mathrm{mM}$ phenylmethylsulfonyl fluoride (PMSF) dissolved in methanol for $1 \mathrm{~h}$ before incubation with the antibodies.

Determination of elastolytic activity of bronchial secretions. The elastolytic activity was determined as described by Hornebeck and Schnebli [23] with purified bovine elastin (Sigma) radioactively labeled with ${ }^{3} \mathrm{H}$ (New England Nuclear Corp., Boston). Ten microliters of the bronchial secretion was incubated with $500 \mu \mathrm{g}$ of ${ }^{3} \mathrm{H}$-labeled elastin suspended in $1 \mathrm{~mL}$ of $0.1 M$ Tris ( $\mathrm{pH} \mathrm{8.2)} \mathrm{containing} 0.01 \% 23$ lauryl ether (Brij ${ }^{\circledR} 35$; Sigma) and $0.02 \%$ sodium azide for $16 \mathrm{~h}$ at $37 \mathrm{C}$. The samples were centrifuged at $3300 \mathrm{~g}$ for $10 \mathrm{~min}$. The radioactivity of $100 \mu \mathrm{L}$ of the supernatant was then measured and used for calculating the amount of solubilized elastin. One milligram of completely solubilized ${ }^{3} \mathrm{H}$-labeled elastin corresponded to $145000 \mathrm{cpm}$. Elastolytic activity $\left(\mathrm{U}_{\mathrm{E}}\right)$ was expressed as the number of milligrams of labeled elastin solubilized by $1 \mathrm{~mL}$ of enzyme solution. This enzymatic reaction was linear over the interval tested.

Purified human neutrophil elastase [24] and cathepsin G [25] were used as controls. For determining the concentration of inhibitors that achieved complete inhibition of purified leukocyte elastase and cathepsin $G$, the activity of these enzymes was 
measured with the synthetic substrates Succ-AlaAla-Pro-Val-pNA and Succ-Ala-Pro-Phe-pNA (both from Calbiochem Behring, Luzern, Switzerland) [26].

Inhibition experiments. The ${ }^{125} \mathrm{I}$-fibronectincleaving activity of cystic fibrosis bronchial secretions was also determined after prior incubation of bronchial secretions with the following inhibitors: partially purified $\alpha_{1}$-proteinase inhibitor $\left(\alpha_{1}\right.$-PI; Sigma); PMSF (Sigma); Eglin C, an inhibitor of neutrophil elastase and cathespin G [27]; Ac-Ala-AlaPro-Val- $\mathrm{ChCl}_{2}$ [26], a specific inhibitor of neutrophil elastase; Ac-Ala-Ala-Pro-Phe- $\mathrm{ChCl}_{2}$, a specific inhibitor of cathepsin $G$ [26] (both peptides from Enzyme Systems Products, Livermore, Calif); and $o$-phenanthroline (Sigma), an inhibitor of metalloproteases such as pseudomonas elastase [28]. We also inactivated the proteolytic activity of cystic fibrosis bronchial secretions by heating at different temperatures.

Assessment of proteolysis of cellular fibronectin. Because plasma fibronectin and cellular fibronectin have different subunit structures [29], we studied the proteolytic effect of cystic fibrosis bronchial secretions on cellular fibronectin of airway mucosa. Cellular fibronectin was revealed by direct immunofluorescence with an FITC-conjugated [30] antibody to fibronectin that had been raised in rabbits. Sections of frozen lung tissue $4 \mu \mathrm{m}$ thick were fixed on glass slides coated with poly-I-lysine (Sigma) by exposure to acetone for $2 \mathrm{~min}$. The preparation was rinsed three times with PBS, and a drop of FITCconjugated antiserum to fibronectin was deposited on the tissue section. Fluorescence was observed in a fluorescent light microscope after incubation for 30 min with the antibody, subsequent rinsing with PBS, and exposure to $90 \%$ glycerol [31]. Immunofluorescent fibronectin was observed after incubation of lung tissue sections with cystic fibrosis bronchial secretions. No fluorescence was observed when the antibody to fibronectin was adsorbed with purified fibronectin before incubation with the lung tissue. Quenching of fluorescence by bronchial secretions was excluded by an experiment in which the cystic fibrosis bronchial secretion had been incubated with an excess amount of Eglin $\mathrm{C}(100 \mu M)$ before incubation with lung tissue sections.

Statistical analysis. Results are given as mean $\pm \mathrm{SD}$ values. Comparisons were made with the Mann-Whitney test, and correlations were analyzed with the Spearman correlation coefficient.

\section{Results}

Elastolytic and ${ }^{125}$ I-fibronectin-cleaving activities and protein concentration of bronchial secretions and saliva. Bronchial secretions from patients with cystic fibrosis and patients with acute exacerbations of chronic bronchitis had a significantly higher mean fibronectin-cleaving activity than did bronchial secretions from patients with chronic bronchitis without acute exacerbation $(P<.01)$ and than did saliva from patients with cystic fibrosis $(P<.01)$ and normal individuals $(P<.01$; table 1$)$. Saliva from patients with cystic fibrosis had significantly higher mean fibronectin-cleaving activity than that from normal individuals $(P<.01)$.

The elastolytic activity of cystic fibrosis bronchial secretions $\left(1.61 \pm 0.85 \mathrm{U}_{E}\right)$ was significantly higher than the elastolytic activity of bronchial secretions from patients with chronic bronchitis and acute exacerbation $\left(0.42 \pm 0.33 \mathrm{U}_{\mathrm{E}}\right)$. No measureable elastolytic activity was found in bronchial secretions from those with chronic bronchitis without acute exacerbation and in saliva from patients with cystic fibrosis and normal individuals. The elastolytic activity of the bronchial secretions obtained by bronchoscopy of two patients with cystic fibrosis and six patients with chronic bronchitis correlated well with that of the morning sputum sample of the same day, and no significant differences were observed in samples of bronchial secretions diluted with $0.9 \% \mathrm{NaCl}$ and shaken by hand before centrifugation and those prepared by ultracentrifugation starting from the same sample. Because the precise quantitation of leukocytes in bronchial secretions is not feasible owing to the viscosity of the samples and because our previous studies had shown a good correlation between semiquantitative determination of leukocyte counts and elastolytic activity of bronchial secretions [11, 12], we made no attempt to quantitate neutrophils in the secretions.

None of the culture supernatants of the three elastase-producing strains of $P$. aeruginosa had significant ${ }^{125}$ I-fibronectin-cleaving activity.

The total protein concentration was significantly higher in bronchial secretions from patients with cystic fibrosis and those with chronic bronchitis with acute exacerbations than in the bronchial secretions from those with chronic bronchitis without acute exacerbation and in the samples of saliva from patients with cystic fibrosis and normal individuals $(P<.01)$. The mean protein concentration of cystic fibrosis 
Table 1. Elastolytic and fibronectin-cleaving activities and protein concentration of bronchial secretions and saliva.

\begin{tabular}{|c|c|c|c|c|c|}
\hline \multirow[b]{2}{*}{ Specimen, group } & \multicolumn{2}{|c|}{ No. tested } & \multirow{2}{*}{$\begin{array}{c}\text { Elastolytic } \\
\text { activity }\left(\mathrm{U}_{\mathrm{E}}\right)\end{array}$} & \multirow{2}{*}{$\begin{array}{c}\text { Fibronectin-cleaving } \\
\text { activity }(\%)\end{array}$} & \multirow{2}{*}{$\begin{array}{c}\text { Total protein } \\
\text { concentration }(\mathrm{g} / \mathrm{L})\end{array}$} \\
\hline & Patients & Samples & & & \\
\hline \multicolumn{6}{|l|}{ Bronchial secretions } \\
\hline Cystic fibrosis & 24 & 194 & $1.61 \pm 0.85^{*}$ & $39.1 \pm 15.2$ & $5.8 \pm 3.8$ \\
\hline \multicolumn{6}{|l|}{ Chronic bronchitis } \\
\hline With acute exacerbations & 16 & 24 & $0.42 \pm 0.33^{* \dagger}$ & $37.5 \pm 16.2 \ddagger$ & $4.0 \pm 3.6$ \\
\hline Without acute exacerbations & 10 & 12 & $<0.05^{\dagger}$ & $3.3 \pm 3.4 \ddagger$ & $2.4 \pm 2.7$ \\
\hline \multicolumn{6}{|l|}{ Saliva } \\
\hline Cystic fibrosis & 14 & 24 & $<0.05$ & $8.2 \pm 19.0$ & $2.4 \pm 2.1$ \\
\hline Normal & 18 & 18 & $<0.05$ & $4.0 \pm 9.0$ & $1.4 \pm 0.7$ \\
\hline
\end{tabular}

NOTE. Elastolytic activity is $\mathrm{mg}$ of ${ }^{3} \mathrm{H}$-labeled elastin solubilized $(16 \mathrm{~h}$ at $37 \mathrm{C})$ by $1 \mathrm{~mL}$ of undiluted sample. Fibronectincleaving activity is the percentage of the cpm of ${ }^{125} \mathrm{I}$-fibronectin released in the supernatant divided by the radioactivity of the total sample. All tests were done in triplicate, and the background (determined by incubation of the substrates without the source of enzymes) was subtracted. Data are mean \pm SD values. For statistical evaluation the Mann-Whitney test was used.

$* P<.01$.

$\dagger P<.01$.

$\ddagger P<.01$.

bronchial secretions was significantly higher $(P$ $<.05)$ than that of bronchial secretions from patients with chronic bronchitis and acute exacerbations.

Inhibition experiments. The elastolytic activity of all samples of bronchial secretions was inhibited $86 \%-95 \%$ by $2 \mathrm{mM}$ PMSF, a finding demonstrating that most of it was due to serine proteases (table 2).

To determine which enzyme(s) might be responsible for the fibronectin-cleaving activity, we used specific inhibitors of neutrophil elastase, cathepsin $\mathrm{G}$, or both. The inhibition as a percentage of fibronectin-cleaving activity of cystic fibrosis bronchial secretions, purified neutrophil elastase, and cathep$\sin \mathrm{G}$ is shown in table 2. Purified $\alpha_{1}-\mathrm{PI}, \mathrm{PMSF}$, and Eglin $\mathrm{C}$ inhibited the fibronectin-cleaving activity of cystic fibrosis bronchial secretions substantially $(80 \%-90 \%)$ as well as that of purified neutrophil elastase and cathepsin G, with one exception: As expected [32], the fibronectin-cleaving activity of purified cathepsin $G$ was inhibited only $37 \%$ by partially purified $\alpha_{1}$-PI at the concentration used. We then tried to distinguish fibronectin-cleaving activity due to elastase from that due to cathepsin $G$ by using the elastase-specific [26] inhibitor Ac-Ala-Ala-Pro-

Table 2. Inhibition of ${ }^{125}$ I-fibronectin-cleaving activity by various inhibitors and inactivation by heating.

\begin{tabular}{lccc}
\hline & \multicolumn{2}{c}{ Inhibition (\%) of ${ }^{125}$ I-fibronectin-cleaving activity of } \\
\cline { 2 - 4 } Inhibitor (concentration) & $\begin{array}{c}\text { Cystic fibrosis } \\
\text { bronchial secretions }\end{array}$ & $\begin{array}{c}\text { Purified } \\
\text { neutrophil elastase }\end{array}$ & $\begin{array}{c}\text { Purified } \\
\text { cathepsin G }\end{array}$ \\
\hline $\begin{array}{l}\alpha_{1} \text {-PI }(4 \mu M) \\
\text { PMSF }(2 \mathrm{mM})\end{array}$ & $80 \pm 7(9)$ & $89 \pm 3(4)$ & $37 \pm 9(4)$ \\
Eglin C $(12.5 \mu M)$ & $90 \pm 5(11)$ & $95 \pm 2(7)$ & $91 \pm 2(7)$ \\
Ac-Ala-Ala- & $87 \pm 8(11)$ & $98 \pm 3(7)$ & $99 \pm 1(7)$ \\
$\quad$ Pro-Val-ChCl $(1 \mathrm{mM})$ & $67 \pm 9(10)$ & $82 \pm 3(4)$ & $28 \pm 9(4)$ \\
Ac-Ala-Ala- & & & \\
$\quad$ Pro-Phe-ChCl $(1 \mathrm{mM})$ & $84 \pm 9(9)$ & $89 \pm 3(4)$ & $93 \pm 3(4)$ \\
Heating at & & & \\
$\quad 60 \mathrm{C}$ for $15 \mathrm{~min}$ & $11 \pm 6(2)$ & $22 \pm 8(3)$ & $87 \pm 3(3)$ \\
$\quad 80$ C for $15 \mathrm{~min}$ & $96 \pm 2(2)$ & $98 \pm 1(3)$ & $94 \pm 2(3)$ \\
\hline
\end{tabular}

NOTE. Fibronectin-cleaving activity of bronchial secretions and purified neutrophil enzymes was tested simultaneously in the presence and in the absence of the indicated inhibitors or after heat inactivation of the samples. Inhibition is expressed as $100 \times$ (activity of the sample with inhibitor/activity of the sample without the inhibitor). Bronchial secretions were preincubated with the inhibitor for $15 \mathrm{~min}$. Data are mean $\pm \mathrm{SD}$ values (no. of bronchial secretions tested in triplicate). 
Val-ChCl 2 and the cathepsin G-specific inhibitor [26] Ac-Ala-Ala-Pro-Phe-ChCl . We first determined the concentration of inhibitor inhibiting the esterolytic activity of purified elastase and cathepsin $\mathrm{G}$; the esterolytic activity on the specific substrates of both enzymes was inhibited efficiently $(>95 \%)$ when the inhibitor was used at $20 \mu M$. However, the fibronectin-cleaving activity of purified elastase and cathep$\sin \mathrm{G}$ was not substantially reduced when we used the inhibitor at this concentration, and we therefore increased the concentration of inhibitor to $1 \mathrm{mM}$. Under these conditions the elastase-specific inhibitor partially inhibited the fibronectin-cleaving activity of cathepsin $G(28 \%)$, whereas the cathepsin G-specific inhibitor also inhibited the fibronectin-cleaving activity of purified elastase by $84 \%$. The fibronectin-cleaving activity of cystic fibrosis bronchial secretions was inhibited $67 \%$ by the elastasespecific and $84 \%$ by the cathepsin G-specific inhibitor. Because cathepsin $G$ is less resistant to heat than is elastase [33], we also tested the heat resistance of the fibronectin-cleaving activity of cystic fibrosis bronchial secretions and of purified elastase and cathepsin G. Whereas the fibronectin-cleaving activity of purified elastase and the cystic fibrosis bronchial secretions was inactivated only after heating of the samples at $80 \mathrm{C}$ for $15 \mathrm{~min}$, that of purified cathepsin $G$ was inactivated $87 \%$ after heating at $60 \mathrm{C}$ for $15 \mathrm{~min}$.

From these inhibition experiments we concluded that $(I)$ the fibronectin-cleaving activity of cystic fibrosis bronchial secretions was inhibited best by PMSF and Eglin C (90\% and $87 \%$, respectively), which inhibit both cathepsin $G$ and elastase; (2) the specific chloromethylketone inhibitors of cathepsin $\mathrm{G}$ and elastase did not allow us to distinguish between these two enzymes as a source of fibronectincleaving activity in cystic fibrosis bronchial secretions because they lost their specificity at a concentration of $1 \mathrm{mM}$; and (3) the heat resistance of the fibronectin-cleaving activity of cystic fibrosis bronchial secretions was similar to that of elastase rather than of cathepsin G. Phenanthroline $(1 \mathrm{mM})$, which inhibited the elastolytic activity of $P$ aeruginosa culture supernatant by $>90 \%$, did not inhibit the fibronectin-cleaving or the elastolytic activity of cystic fibrosis bronchial secretions.

Kinetics of proteolysis of purified fibronectin by cystic fibrosis bronchial secretions, purified elastase, and cathepsin $G$. To test further whether cathep$\sin \mathrm{G}$, other enzymes, or both contributed to the fibronectin-cleaving activity of cystic fibrosis bronchial secretions in addition to elastase, we examined the time course and the kinetics of the breakdown of purified fibronectin by these bronchial secretions and compared the apparent molecular weights of fibronectin breakdown products generated by these three sources of enzymatic activity. The breakdown pattern of fibronectin by a pool of cystic fibrosis bronchial secretions is shown in figure 1, top, and that of a mixture of purified elastase and cathepsin $\mathrm{G}(3: 1)$ is shown in figure 1 , bottom, at $0,1,5,10$, 15,30 , and $60 \mathrm{~min}$ of incubation at $37 \mathrm{C}$. After 1 min of incubation with the cystic fibrosis bronchial secretion the two monomers of fibronectin with apparent molecular weights of 220000 were split into multiple fragments. The molecular weights of some fragments were identical to those generated by elastase and cathepsin G: $181000,164000,152000$, $141000,138000,108000$, and 84000 . Although major breakdown products had similar molecular weights, the time course of appearance was clearly different in figure 1, top and bottom. These experiments showed that $(l)$ purified fibronectin was completely hydrolyzed by the cystic fibrosis bronchial secretion as well as by elastase and cathepsin $G$ within $1 \mathrm{~min}$ and (2) although some breakdown products of fibronectin generated by the cystic fibrosis bronchial secretion had molecular weights identical to those generated by elastase and cathepsin G, the time course of degradation and the molecular weights of several fragments were different.

Zymographs. On the zymographs (figure 2) copolymerized fibronectin appeared as dark staining. In figure 2 the first four lanes were loaded with 1.2 and $2.4 \mu \mathrm{g}$ of fibronectin, lanes 5 and 6 with 3 $\mu \mathrm{L}$ of purified neutrophil elastase, lanes 7 and 8 with a combination of $3 \mu \mathrm{L}$ of purified elastase and $1 \mu \mathrm{L}$ of purified cathepsin G, lanes 9 and 10 with $1 \mu \mathrm{L}$ of purified cathepsin G, and lanes 11 and 12 with $1 \mu \mathrm{L}$ of a pool of cystic fibrosis bronchial secretions. Figure 2 shows an identically migrating, clear double band for lanes 7 and 8 and lanes 11 and 12 . The results were identical for a $\mathrm{pH}$ of the incubation buffer of $6.8,7.4$, and 8.3. Thus this experiment demonstrated that the fibronectin-cleaving activity of cystic fibrosis bronchial secretions comigrated with purified elastase and cathepsin G. No other zones of fibronectin cleavage were observed under our experimental conditions. Control experiments confirmed that the clear bands corresponded to degradation of fibronectin by proteases. When the 


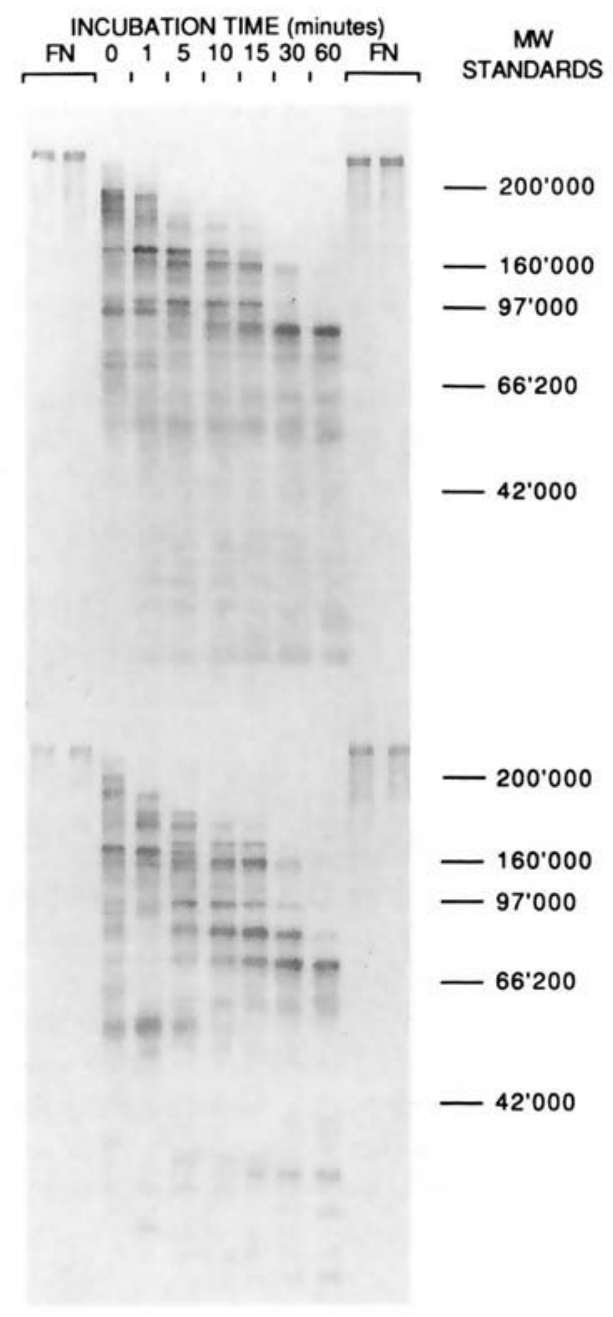

Figure 1. Top, proteolytic activity of $1 \mu \mathrm{L}$ of a pool of cystic fibrosis bronchial secretions against purified fibronectin after $0,1,5,10,15,30$, and $60 \mathrm{~min}$ of incubation at $37 \mathrm{C}$. The proteolysis of fibronectin was examined by PAGE (running gel, 7.5\% [wt/vol]) and subsequent immunoblotting. The molecular weights were monitored using standard proteins (Biorad). Bottom, an identical experiment, in which $3 \mu \mathrm{L}$ of purified elastase and $1 \mu \mathrm{L}$ of purified cathepsin $\mathrm{G}$ were incubated with fibronectin. Major fragments with molecular weights of 181000,164000 , $152000,141000,138000,108000$, and 84000 appeared after incubation of fibronectin with the bronchial secretion (top) and with purified enzymes (bottom), but the time course of appearance of fragments and the molecular weights of other fragments were different. Lanes 1 , 2,10 , and 11 were loaded with $1.2 \mu \mathrm{g}$ of purified fibronec$\operatorname{tin}(F N)$.

bronchial secretion and the purified neutrophil enzymes were heated at $90 \mathrm{C}$ for $15 \mathrm{~min}$ before electrophoresis, no clear bands appeared. Degradation of the rabbit antibody to fibronectin or the antibody

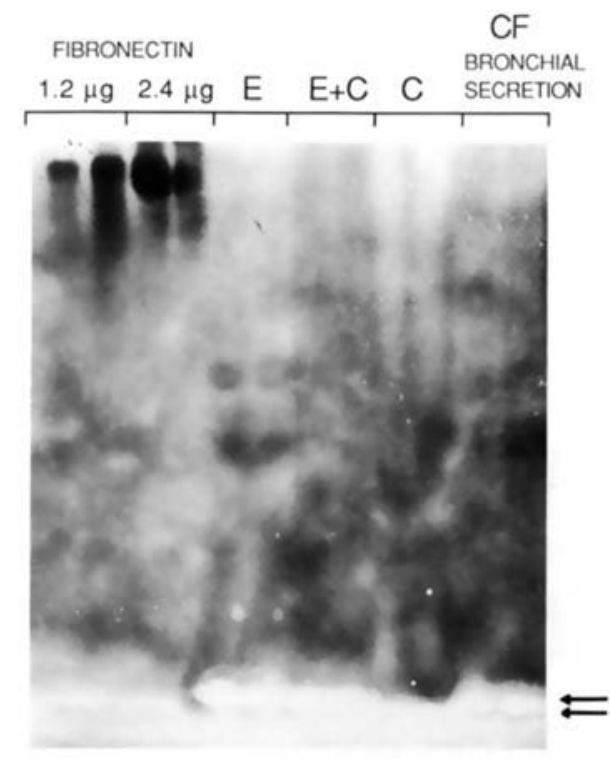

Figure 2. Zymograph in which the proteolytic effect of $1 \mu \mathrm{L}$ of purified elastase ( $E$; lanes 5 and 6 ), $3 \mu \mathrm{L}$ of purified elastase plus $1 \mu \mathrm{L}$ of purified cathepsin $\mathrm{G}(E+C$; lanes 7 and 8$), 1 \mu \mathrm{L}$ of purified cathepsin $\mathrm{G}(C$; lanes 9 and 10 ), and $1 \mu \mathrm{L}$ of a pool of cystic fibrosis $(C F)$ bronchial secretions (lanes 11 and 12 ) on purified fibronectin copolymerized in a polyacrylamide gel $(7.5 \%[\mathrm{wt} / \mathrm{vol}])$ was evaluated after electrophoresis of the unheated samples $(40 \mathrm{C})$ through the gel. Purified fibronectin (1.2 or $2.4 \mu \mathrm{g}$ ) was loaded on lanes $1-4$. The two arrows point to areas of proteolysis of fibronectin, which appear as clear bands. The fibronectin-cleaving activity of cystic fibrosis bronchial secretions comigrated with the combination of elastase plus cathepsin $G$ in a double band.

to rabbit IgG by enzymes transferred to the Novilon membrane was excluded because the clear zones appeared also when the Novilon membrane was treated with $2 \mathrm{~m} M$ PMSF before incubation with the antibodies.

Because free granulocyte elastase can be quantitated in cystic fibrosis bronchial secretions by measuring elastolytic activity, we measured the mean elastolytic activities in these bronchial secretions in relation to bacterial colonization (with and without $P$. aeruginosa), age, and disease stage (table 3 ) to determine precisely the amount of enzymes responsible for fibronectin-cleaving activity. Bronchial secretions from patients with cystic fibrosis colonized with $P$. aeruginosa had significantly higher mean elastolytic activity than those from patients not colonized with $P$. aeruginosa $(P<.01)$, patients $>17$ y old had significantly higher mean elastolytic activities than 
Table 3. Elastolytic activity and protein concentration of cystic fibrosis bronchial secretions.

\begin{tabular}{|c|c|c|c|c|}
\hline \multirow[b]{2}{*}{$\begin{array}{l}\text { Cystic fibrosis } \\
\text { group }\end{array}$} & \multicolumn{2}{|c|}{ No. of } & \multirow[b]{2}{*}{$\begin{array}{c}\text { Elastolytic } \\
\text { activity }\left(\mathrm{U}_{\mathrm{E}}\right)\end{array}$} & \multirow[b]{2}{*}{$\begin{array}{c}\text { Total protein } \\
\text { concentration }(\mathrm{g} / \mathrm{L})\end{array}$} \\
\hline & Patients & $\begin{array}{l}\text { Bronchial } \\
\text { secretions }\end{array}$ & & \\
\hline All patients & 24 & 194 & $1.61 \pm 0.85$ & $5.8 \pm 3.8$ \\
\hline \multicolumn{5}{|l|}{ P. aeruginosa } \\
\hline Colonized & 15 & 111 & $1.82 \pm 0.88^{*}$ & $5.7 \pm 4.3$ \\
\hline Not colonized & 9 & 83 & $1.28 \pm 0.72^{*}$ & $5.9 \pm 3$ \\
\hline \multicolumn{5}{|l|}{ Age (y) } \\
\hline $17-21$ & 9 & 44 & $2.14 \pm 0.9 \dagger$ & $6.8 \pm 5.1$ \\
\hline $11 / 4-81 / 3$ & 10 & 54 & $1.23 \pm 0.69^{\dagger}$ & $4.5 \pm 3.2$ \\
\hline \multicolumn{5}{|l|}{ Disease stage } \\
\hline II & 6 & 21 & $1.39 \pm 0.6 \ddagger$ & $5.2 \pm 2.1$ \\
\hline$I I I+I V$ & 6 & 30 & $3.0 \pm 1.4 \ddagger$ & $10.1 \pm 4.6$ \\
\hline
\end{tabular}

NOTE. Elastolytic activity is mg of ${ }^{3} \mathrm{H}$-labeled elastin solubilized $(16 \mathrm{~h}$ at $37 \mathrm{C})$ by $1 \mathrm{~mL}$ of undiluted sample. Data are mean $\pm \mathrm{SD}$ values. The Mann-Whitney test was used for comparisons between groups.

${ }^{*} P<.01$.

$\dagger P<.01$.

$\ddagger P<.01$.

did those less than nine years old $(P<.01)$, and bronchial secretions from patients who remained at disease stage II throughout the observation period had significantly lower mean elastolytic activity than those from patients with disease stages III and IV, regardless of their bacterial colonization status ( $P$ $<.01)$. Two patients not colonized with $P$. aeruginosa were in the group including disease stages III and IV.

The mean \pm SD elastolytic activity of the culture supernatants of three elastase-producing strains of $P$ a aeruginosa was $1.2 \pm 0.35 \mathrm{U}_{\mathrm{E}}$. Purified leukocyte elastase had an elastolytic activity of $7.78 \pm 0.59$ $\mathrm{U}_{\mathrm{E}}$, and the fibronectin-cleaving activity of $1 \mu \mathrm{L}$ of purified elastase and cathepsin $G$ was $33 \% \pm 4 \%$ and $30 \% \pm 3 \%$, respectively.

Proteolysis of cellular fibronectin by cystic fibrosis bronchial secretions. We used frozen sections of lung tissue from an individual without cystic fibrosis to reveal cellular fibronectin on the surface of mucosal cells before and after incubation of the tissue with a cystic fibrosis bronchial secretion for 1 $\min$. The results of three separate experiments were similar. Figure 3 shows the effect of the cystic fibrosis bronchial secretion of fibronectin of airway mucosal cells. Figure $3 \mathrm{~A}$ shows the lung tissue section stained with hematoxylin and eosin. Immunofluorescent fibronectin appears in figure 3B. After incubation of the lung tissue section with a cystic fibrosis bronchial secretion for $1 \mathrm{~min}$, the immunofluorescent fibronectin had disappeared (figure $3 \mathrm{C}$ ).
When the cystic fibrosis bronchial secretion was preincubated with an excess amount of Eglin C, incubation of this secretion with the lung tissue had no effect on tissue fibronectin fluorescence. A control experiment had shown that the bright immunofluorescence observed before incubation with the cystic fibrosis bronchial secretion could not be observed when the FITC-conjugated antibody to fibronectin was adsorbed with purified fibronectin before use.

\section{Discussion}

The results of our study show that bronchial secretions from patients with cystic fibrosis and patients with chronic bronchitis with acute exacerbations contained large amounts of ${ }^{125}$ I-fibronectin-cleaving activity, whereas only small amounts were found in saliva from patients with cystic fibrosis and normal individuals (table 1). In contrast to the patients with chronic bronchitis, in whom the ${ }^{125}$ I-fibronectincleaving activity was present only during acute exacerbations, fibronectin-cleaving activity was found in all 194 samples of bronchial secretions from patients with cystic fibrosis who were followed up for a period of $4.5 \mathrm{y}$.

The test that we developed for measuring fibronectin-cleaving activity with ${ }^{125}$ I-fibronectin bound to Sepharose beads as a substrate did not allow us to quantitate the enzyme(s) involved precisely because the enzymatic reaction was not linear, regardless of the enzyme source tested (bronchial secretions 
Figure 3. $A$, hematoxylin and eosin staining of a $4-\mu \mathrm{m}$-thick section of deep-frozen lung tissue. Immunofluorescent staining of fibronectin was done on a similar section $(B)$ before and $(C)$ after $1 \mathrm{~min}$ of incubation in a moist chamber with $200 \mu \mathrm{L}$ of a cystic fibrosis bronchial secretion. After incubation, most of the immunofluorescent fibronectin had disappeared.
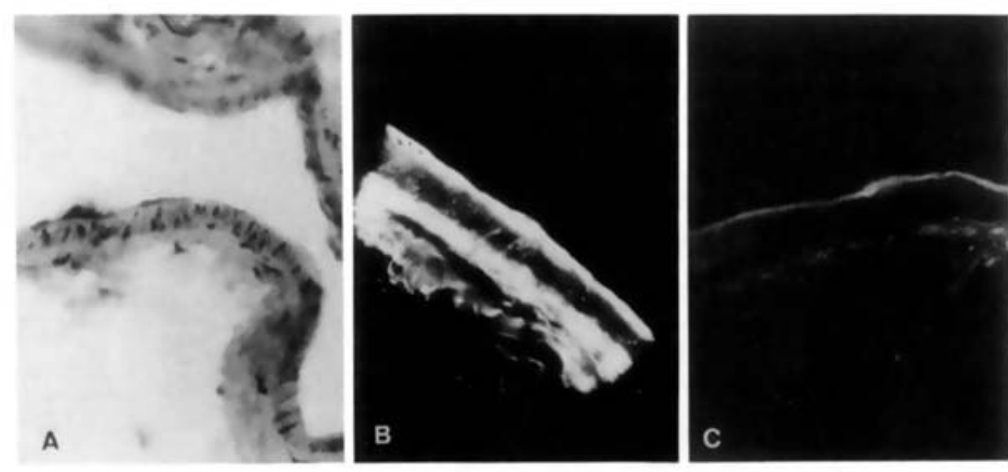

or purified neutrophil elastase and cathepsin G). This observation may be explained by the presence of several cleavage sites on the fibronectin molecule, as shown by the degradation pattern of unlabeled fibronectin (figure 1). The time course of degradation of unlabeled fibronectin confirms the rapidity of proteolysis of fibronectin and argues against the hypothesis that the radioactively labeled fibronectin was more susceptible to proteolysis because of the labeling procedure. We therefore attempted first to identify the enzymes responsible for fibronectin cleavage by bronchial secretions. For this purpose we used inhibitors and determined the degradation pattern of purified fibronectin by bronchial secretions in comparison to purified elastase and cathep$\sin G$, which were the enzymes most likely involved in fibronectin cleavage $[29,34]$. Finally, we used zymographs $[21,22]$ to estimate the migration of fibronectin-degrading enzymes in bronchial secretions, in comparison to the migration of purified elastase and cathepsin G.

The inhibition of $90 \%$ and $87 \%$ of ${ }^{125}$ I-fibronectin-cleaving activity by PMSF and Eglin C, respectively, showed that the enzymes involved were most likely serine proteases, such as neutrophil elastase and cathepsin G [24-26, 32, 33] (table 2). The two inhibitors Ac-Ala-Ala-Pro-Val-ChCl ${ }_{2}$ and Ac-AlaPro-Phe- $\mathrm{ChCl}_{2}$, which are specific for neutrophil elastase and cathepsin G, respectively, when used with purified enzymes [26], did not allow us to distinguish further the enzymes involved in the ${ }^{125}$ Ifibronectin-cleaving activity of cystic fibrosis bronchial secretions because the inhibitors lost their specificity at a concentration of $1 \mathrm{~m} M$, as demonstrated by inhibition of the activity of purified elastase and cathepsin $\mathrm{G}$ (table 2). We observed this problem with Eglin C [12], for which the concentra- tions required for inhibiting the elastolytic activity of cystic fibrosis bronchial secretions was much higher than for an identical amount of elastolytic activity of purified neutrophil elastase. These observations suggest that such specific inhibitors are not always suitable tools for identifying enzymatic activities within biologic fluids. In biologic fluids these inhibitors may bind unspecifically to components other than enzymes or to enzymes without activity on the substrate tested. When we compared the time course of degradation of purified fibronectin by cystic fibrosis bronchial secretions and purified neutrophil elastase and cathepsin G (either alone or in combination), we found that seven breakdown products with identical molecular weights were generated by cystic fibrosis bronchial secretions (figure 1, top) as well as by the combination of elastase and cathep$\sin \mathrm{G}$ (figure 1, bottom). Because human neutrophils contain $\sim 3 \mu \mathrm{g}$ of elastase for $1 \mu \mathrm{g}$ of cathepsin $\mathrm{G}$, we used purified elastase and cathepsin $\mathrm{G}$ in a mixture of $3: 1$ [33]. However, the time course of degradation and the molecular weights of other fragments were clearly different. This finding raises the question of whether other enzymes, either from bacteria or other endogenous protease(s), were involved in the degradation of fibronectin or of its fragments generated by neutrophil proteases in cystic fibrosis bronchial secretions or whether this activity was related to a different proportion of elastase/cathepsin $\mathrm{G}$ in these bronchial secretions than the proportion of 3:1 that was used for the purified enzymes. The best evidence that neutrophil elastase and cathepsin $G$ were the main enzymes involved in fibronectincleaving activity of cystic fibrosis bronchial secretions is shown on the zymographs (figure 2). These experiments showed that over a $\mathrm{pH}$ range of the incubation buffer ranging from 6.8 to 8.3 , fibronectin- 
cleaving activity of cystic fibrosis bronchial secretions comigrated with the fibronectin-cleaving activity of a mixture (3:1) of purified neutrophil elastase and cathepsin G.

Taken together, these results suggest that neutrophil elastase and cathepsin $G$ are both involved in the fibronectin-cleaving activity of cystic fibrosis bronchial secretions.

In the experiments described above we used fibronectin purified from plasma [17]. Although plasma and cellular fibronectins are very similar in molecular properties (they have nearly identical amino-acid compositions and secondary and tertiary structures), cellular fibronectin, in contrast to plasma fibronectin, is present not only in dimers but also in multimers [8]. We therefore examined the effect of cystic fibrosis bronchial secretions on microscopic sections of lung tissue and especially of airway mucosa by revealing cellular fibronectin before and after incubation of the tissue with a cystic fibrosis bronchial secretion. Figure 3 clearly shows a striking decrease of fibronectin fluorescence on the surface of mucosal cells as well as of intercellular fibronectin after exposure to the cystic fibrosis bronchial secretion. This experiment demonstrated that cystic fibrosis bronchial secretions also had proteolytic activity on cell-bound fibronectin.

We knew from previous studies [11-13] that bronchial secretions from patients with cystic fibrosis infected with $P$. aeruginosa contained high amounts of free neutrophil elastase (a mean of $55 \mu \mathrm{g} / \mathrm{mL}$ of sputum). In contrast to the kinetics of proteolysis of ${ }^{125}$ I-fibronectin by the neutrophil enzymes elastase and cathepsin G, the proteolytic degradation of ${ }^{3} \mathrm{H}$ labeled elastin by these enzymes was linear over the incubation period tested. To determine precisely the amount of neutrophil elastase, we measured elastolytic activity in bronchial secretions from patients colonized with $P$. aeruginosa as well as patients not colonized with this organism and compared free elastolytic activity of these two groups, as well as that of bronchial secretions of younger vs. older patients and patients with high vs. low disease stages (table 3). Significantly higher elastolytic activity in bronchial secretions was found in older vs. younger patients, in patients with high vs. low disease stages, and in those colonized with $P$. aeruginosa vs. the patients colonized with other bacterial pathogens. These values, however, represent elastolytic activity per milliliter of sputum and do not reflect the total elastase burden to which the airways of the patients were exposed. As we showed previously [12], the sputum quantity and therefore the total elastase burden decrease significantly after antimicrobial treatment in patients with cystic fibrosis colonized with $P$. aeruginosa. Because the kinetics of ${ }^{125}$ I-fibronectin degradation were not comparable to those of ${ }^{3} \mathrm{H}$ labeled elastin degradation, no correlation between the enzymatic activities on these two substrates could be calculated.

Because in all these patients the ${ }^{125} \mathrm{I}$-fibronectin-cleaving activity of saliva was much lower than that of bronchial secretions, it is conceivable that the fibronectin-cleaving activity from bronchial secretions rather than from saliva led to degradation of surface fibronectin of buccal epithelial cells. Indeed, bronchial secretions reach the oropharynx during coughing and during chest physiotherapy, and because they contain high amounts of potent proteolytic enzymes, they might contribute to the alteration of epithelial surfaces of the upper respiratory tract. An increase in elastase content in saliva of postoperative patients was found to precede colonization with gram-negative bacilli [35]. The origin of the elastase was most likely from neutrophils, according to the inhibition experiments shown in this study, but whether elastase was released by neutrophils within the upper respiratory tract - for example, in crevicular fluid - or whether it may have originated from the lower respiratory tract was not clear.

Although the correlation between colonization with gram-negative bacilli of the upper respiratory tract and the absence of fibronectin on buccal epithelial surfaces is well documented [7-10, 35], the significance of the absence of surface fibronectin from the lower-respiratory-tract epithelium as a factor favoring colonization with gram-negative bacteria is unknown. Acid injury favors adherence of mucoid and nonmucoid $P$. aeruginosa to tracheal epithelium [36], but whether acid injury destroys fibronectin on cell surfaces is not known. Although we have shown that fibronectin was present on the surface of epithelial cells of small airways of normal human lung tissue and that surface fibronectin disappeared after incubation of the tissue for $1 \mathrm{~min}$ with cystic fibrosis bronchial secretions, the correlation of adherence of $P$. aeruginosa to epithelial cell surfaces of the lower respiratory tract of patients with cystic fibrosis and absence of surface fibronectin remains to be established. That the proteolytic activity of neutrophil elastase and cathepsin $G$ is not limited to fibronectin is certain: Elastase destroys the three 
major structural proteins of the lung and the airways, which are elastin, collagen, and proteoglycans [37, 38]. Therefore, it is likely that these proteases produce extensive damage to airway epithelia. Other factors favoring colonization with $P$. aeruginosa of the lower respiratory tract, such as adherence to mucins, have been found [39], but the peculiar shift from colonization with gram-positive to gram-negative bacilli in patients with cystic fibrosis cannot be explained by this finding alone, unless the binding properties of cystic fibrosis mucin also changed with time. What does change with time is the elastase burden to which the airways are continuously exposed (table 3).

In summary, we have shown that bronchial secretions, much more than saliva, from patients with cystic fibrosis contain fibronectin-cleaving activity over prolonged periods, in contrast to those from patients with chronic bronchitis, in which fibronectin-cleaving activity was present only during acute exacerbations. This fibronectin-cleaving activity was mostly due to neutrophil elastase and cathepsin $\mathrm{G}$ and was shown to degrade surface fibronectin on epithelial cells of small airways of normal lung tissue. Our results suggest that fibronectin-cleaving activity of bronchial secretions rather than saliva may favor the colonization with $P$. aeruginosa of the upper respiratory tract of patients with cystic fibrosis and that the role of proteolytic activity on surface fibronectin of the lower respiratory tract in the persistence of colonization with $P$. aeruginosa should be further studied. Prevention of colonization with $P$. aeruginosa of the upper respiratory tract of patients with cystic fibrosis could be attempted by using topical elastase and cathepsin G inhibitors such as Eglin C to protect surface fibronectin of buccal epithelial cells, as was suggested for the prevention of colonization with gram-negative bacilli in postoperative patients [35]. If the adherence of $P$. aeruginosa to epithelial cell surfaces of the lower respiratory tract is mediated by a similar mechanism, systemic rather than local treatment with protease inhibitors would be required. No synthetic inhibitor of neutrophil elastase and cathepsin $G$ is currently available for clinical studies. To our knowledge, only one therapeutic approach was shown to decrease the frequency of colonization with $P$. aeruginosa of the respiratory tract of patients with cystic fibrosis: In a placebo-controlled study, patients with cystic fibrosis receiving alternate-day prednisone treatment were less often colonized with P. aeruginosa [40]. The anti-inflammatory effect of prednisone may have led to a decrease of migration of neutrophils into the respiratory tract, with a concomitant decrease of the protease burden originating from neutrophils within the airways. We believe that compounds that potentially lead to a decrease of the protease burden in the airways of patients with cystic fibrosis should be evaluated in clinical studies.

\section{References}

1. Pennington JE, Wolff SM, Puziss M. Summary of a workshop on infections in patients with cystic fibrosis. J Infect Dis 1979;140:252-6

2. Marks MI. The pathogeneis and treatment of pulmonary infections in patients with cystic fibrosis. J Pediatr 1981; 98:173-9

3. Pier GB. Pulmonary disease associated with Pseudomonas aeruginosa in cystic fibrosis: current status of host-bacterium interaction. J Infect Dis 1985;151:575-80

4. Bruce MC, Poncz L, Klinger JD, Stern RC, Tomashefski JF $\mathrm{Jr}$, Dearborn DG. Biochemical and pathologic evidence for proteolytic destruction of lung connective tissue in cystic fibrosis. Am Rev Respir Dis 1985;132:529-35

5. Sobonya RE, Taussig LM. Quantitative aspects of lung pathology in cystic fibrosis. Am Rev Respir Dis 1986;134:290-5

6. Wheeler WB, Williams M, Matthews W, Colten HR. Progression of cystic fibrosis lung disease as a function of serum immunoglobulin $\mathrm{G}$ levels: a 5-year longitudinal study. J Pediatr 1984;104:695-9

7. Woods DE, Straus DC, Johanson WG, Bass JA. Role of fibronectin in the prevention of adherence of Pseudomonas aeruginosa to buccal cells. J Infect Dis 1981;143:784-90

8. Abraham SN, Beachey EH, Simpson WA. Adherence of Streptococcus pyogenes, Escherichia coli and Pseudomonas aeruginosa to fibronectin-coated and uncoated epithelial cells. Infect Immun 1983;41:1261-8

9. Woods DE, Bass JA, Johanson WG, Straus DC. Role of adherence in the pathogenesis of Pseudomonas aeruginosa lung infection in cystic fibrosis patients. Infect Immun 1980;30:694-9

10. Woods DE, Straus DC, Johanson WG, Bass JA. Role of salivary protease activity in adherence of gram-negative bacilli to mammalian buccal epithelial cells in vivo. J Clin Invest 1981;68:1435-40

11. Suter S, Schaad UB, Roux L, Nydegger UE, Waldvogel FA. Granulocyte neutral proteases and pseudomonas elastase as possible causes of airway damage in patients with cystic fibrosis. J Infect Dis 1984;149:523-31

12. Suter S, Schaad UB, Tegner H, Ohlsson K, Desgrandchamps $D$, Waldvogel FA. Levels of free granulocyte elastase in bronchial secretions from patients with cystic fibrosis: effect of antimicrobial treatment against Pseudomonas aeruginosa. J Infect Dis 1986;153:902-9

13. Goldstein W, Döring G. Lysosomal enzymes from polymorphonuclear leukocytes and proteinase inhibitors in patients with cystic fibrosis. Am Rev Respir Dis 1986;134:49-56

14. Kraemer R, Rüdeberg A, Kläy M, Rossi E. Relationship between clinical conditions, radiographic findings and pul- 
monary functions in patients with cystic fibrosis. Helv Paediatr Acta 1979;34:417-28

15. Chrispin AR, Norman AP. The systematic evaluation of the chest radiograph in cystic fibrosis. Pediatr Radiol 1974; 2:101-6

16. Washington JA. Laboratory procedures in clinical microbiology. New York: Springer-Verlag, 1981

17. Morgenthaler JJ. Hydrophobic chromatography of fibronectin. FEBS Lett 1982;150:81-4

18. McConahey PJ, Dixon FJ. A method of trace iodination of proteins for immunological studies. Int Arch Allergy Appl Immunol 1966;29:185-9

19. Laemmli UK. Cleavage of structural proteins during the assembly of the head of bacteriophage T4. Nature 1970; 227:680-5

20. Gershoni JM, Palade GE. Protein blotting: principles and applications. Anal Biochem 1983;131:1-15

21. Heussen C, Dowdle EB. Electrophoretic analysis of plasminogen activators in polyacrylamide gels containing sodium dodecyl sulfate and copolymerized substrates. Anal Biochem 1980;102:196-202

22. Chen J-M, Chen W-T. Fibronectin-degrading proteases from the membranes of transformed cells. Cell 1987;48:193-203

23. Hornebeck W, Schnebli HP. Effect of different elastase inhibitors on leukocyte elastase preadsorbed to elastin. Hoppe Seylers Z Physiol Chem 1982;363:455-8

24. Baugh RJ, Travis J. Human leukocyte granule elastase: rapid isolation and characterization. Biochemistry 1976;15: 836-41

25. Feinstein G, Janoff A. A rapid method for purification of human granulocyte cationic neutral proteases: purification and characterization of human granulocyte chymotrypsinlike enzyme. Biochim Biophys Acta 1975;403:477-92

26. Nakajima K, Powers JC, Ashe BM, Zimmerman M. Mapping the extended substrate binding site of cathepsin $\mathrm{G}$ and human leukocyte elastase. Studies with peptide substrates related to the $\alpha_{1}$-protease inhibitor reactive site. J Biol Chem 1979;254:4027-32

27. Rink $H$, Liersch $M$, Sieber $P$, Meyer $F$. A large fragment approach to DNA synthesis: total synthesis of a gene for the protease inhibitor Eglin $\mathrm{C}$ from the leech Hirudo medicinalis and its expression in $E$. coli. Nucleic Acid Res 1984;12:6369-87

28. Hudgin RL, Charleson SE, Zimmerman M, Mumford R,
Wood PL. Enkephalinases: selective peptide inhibitors. Life Sci 1981;29:2593-601

29. Yamada KM. Biochemistry of fibronectin. In: Horowitz MI, ed. The glycoconjugates. Vol. 3. New York: Academic Press, 1983:331-62

30. Hudson L, Hay FC. Practical immunology. Oxford: Blackwell Scientific Publications, 1976

31. Zardi L, Siri A, Carnemolla B, Cosulich E, Viale G, Santi L. A simplified procedure for the preparation of antibodies to serum fibronectin. J Immunol Methods 1980;34: $155-65$

32. Schmidt W, Havemann K. Chymotrypsin-like neutral proteases from lysosomes of human polymorphonuclear leukocytes. In: Havemann K, Janoff A, eds. Neutral proteases of human polymorphonuclear leukocytes. Baltimore: Urban and Schwarzenberg, 1978:150-60

33. Schmidt W. Neutrale Proteasen aus menschlichen Leukozyten: Isolierung, Charakterisierung und biologische Wirkungen. Inaugural-dissertation, Marburg, Federal Republic of Germany: University of Marburg, 1975

34. McDonald JA, Baum BJ, Rosenberg DM, Kelman JA, Brin SC, Crystal RG. Destruction of a major extracellular adhesive glycoprotein (fibronectin) of human fibroblasts by neutral proteases from polymorphonuclear leukocyte granules. Lab Invest 1979;40:350-7

35. Dal Nogare AR, Toews GB, Pierce AK. Increased salivary elastase precedes gram-negative bacillary colonization in post-operative patients. Am Rev Respir Dis 1987;135:671-5

36. Ramphal R, Pyle M. Adherence of mucoid and non-mucoid Pseudomonas aeruginosa to acid-injured tracheal epithelium. Infect Immun 1983;41:345-51

37. Gadek JE, Fells GA, Zimmerman RL, Rennard SI, Crystal RG. Antielastases of the human alveolar structures. Implications for the protease-antiprotease theory of emphysema. J Clin Invest 1981;68:889-98

38. Sandberg LB, Soskel NT, Leslie JG. Elastin structure, biosynthesis, and relation to disease states. $\mathrm{N}$ Engl $\mathbf{J}$ Med 1981;304:566-79

39. Ramphal R, Pyle M. Evidence for mucins and sialic acid as receptors for Pseudomonas aeruginosa in the lower respiratory tract. Infect Immun 1983;41:339-44

40. Auerbach HS, Kirkpatrick JA, Williams M, Colten HR. Alternate-day prednisone reduces morbidity and improves pulmonary function in cystic fibrosis. Lancet 1985;2:686-8 